\title{
Evaluation of Thyroid Hormone Changes in Non-Pregnant, Normotensive Pregnant and Pregnancy with Preeclampsia
}

\author{
Dr. Swapan Das ${ }^{1}$, Dr. Debasish Char ${ }^{2}$, Dr. Sanjay Sarkar ${ }^{3}$, \\ Dr. Tushar Kanti Saha ${ }^{4}$, Dr. Sucheta Biswas ${ }^{5}$ \\ ${ }^{1}$ (RMO, Dept. of Gynae and Obstetrics, Bankura Sammilani Medical College \& Hospital, Bankura); ${ }^{2}$ (RMO, \\ Dept. of Gynae and Obstetrics, Bankura Sammilani Medical College \& Hospital, Bankura); ${ }^{3}$ (RMO, Dept. of \\ Medicine, Bankura Sammilani Medical College \& Hospital, Bankura); ${ }^{4}$ (Asst. Prof., Dept. of Community \\ Medicine, NRS Medical College, Kolkata); ${ }^{5}$ (PGT, Dept. of Physiology, Burdwan Medical College \& Hospital, \\ Burdwan)
}

\begin{abstract}
Objective: Normal Thyroid hormone level is essential in maintaining the normal fetal development. The objective of the study was to evaluate the thyroid hormone levels among healthy non-pregnant women with normotensive pregnant women and women with preeclampsia. Materials and methods: In these prospective study 90 women in the age group of $19-36$ are divided into 3 groups consisting of 30 healthy non-pregnant women, 30 healthy normotensive pregnant women and 30 pregnant women with preeclampsia and evaluated for thyroid profile. Results: Serum TT4 and TT3 levels in normotensive pregnant women and preeclamptic women were significantly higher compared to the levels in non-pregnant women. In comparison to the normotensive pregnant women, women with preeclampsia had a non significantly higher TT4 level and significantly lower TT3. In preeclamptic women serum FT4 was marginally raised than in normotensive pregnant subjects but was significantly raised than in nonpregnant subjects. The FT3 level was significantly lower in preeclamptic women than in normotensive pregnant women compared to nonpregnant subjects. TSH levels were significantly higher in both preeclamptic and normotensive pregnant women. Conclusion: The main finding of our study indicates that there is a state of hypothyroidism in normal pregnancy and in preeclampsia and so raised serum TSH occurs. Detection of any changes in thyroid profile in preeclampsia may of health in preventing the development of preeclampsia.
\end{abstract}

Key Words: Pregnancy, Preeclampsia, T3, T4, TSH

\section{Introduction}

Preeclampsia continues to be a major obstetric problem in present day medical practice. It is a leading cause of maternal and foetal / neonatal morbidity and mortality worldwide. Preeclampsia is a multisystem disorder of pregnancy which is characterized by hypertension (blood pressure $>140 / 90 \mathrm{~mm} \mathrm{Hg}$ ) with proteinuria (urinary protein excretion of $>300 \mathrm{mg}$ in 24 hours specimen) after 20 weeks of gestation in previously normotensive nonproteinuric pregnant women [1,2]. The major cause of foetal compromise in preeclampsia is reduced utero-placental perfusion $[3,4]$.

Pregnancy is a physiological process. Maternal physiological adjustments of different organ system occur in pregnancy. The adjustments are - metabolic, circulatory and hormonal [5]. Pregnancy is usually associated with mild hyperthyroidism but preeclamptic women have a high incidence of hypothyroidism that might correlate with the severity of preeclampsia [6,7].

In the circulation whole $T_{4}$ originates from thyroid secretion. But most $T_{3}(80 \%)$ is produced extra thyroidally from deiodination of $\mathrm{T}_{4}$ [9]. In preeclampsia liver, kidney and brain are mostly affected. Due to autointoxication functional disorders in these organs are evident [8]. As liver kidney and muscles are the main organs of peripheral deiodination of $T_{4}$ to $T_{3}$, the serum concentration of $T_{4}$ and $T_{3}$ may different in preeclampsia than in normal pregnancy [5].

The present study examines the thyroid hormonal concentration in healthy normotensive pregnant women, those with preeclampsia and healthy non-pregnant subjects.

\section{Materials And Methods}

The study was performed in the Department of Obstetrics and Gynaecology of B.S. Medical College, Bankura. In this prospective study 90 women divided into 3 groups. Ages ranged from 19 to 36 years. The 3 groups consisted of 30 healthy non-pregnant women, 30 healthy normotensive pregnant women and 30 pregnant women with preeclampsia. Women with bad obstetric history, diabetes mellitus, and chronic illness and with known thyroid disorders were excluded from the study.

Blood samples were drawn from all the subjects following a fast of 12 hours and analysed for serum thyroid stimulating hormone (TSH) total triiodothyronine $\left(\mathrm{TT}_{3}\right)$, free thyroxine $\left(\mathrm{FT}_{4}\right)$ Free triiodothyronine 
(FT3) and total thyroxine $\left(\mathrm{TT}_{4}\right)$ levels. Thyroid profile was measured using CLIA (Chemilumine Scene Immunoassaee) system.

Statistical analysis - All data were expressed as mean \pm SD of number of experiments. Statistical analysis was carried out by student's T-test using SPSS version 10 Software.

\section{Results}

Table -1 shows the demographic characteristics of the study population. All the studied groups had a similar mean age and mean gestational age. BMI were significantly increased in pregnancy groups compared to the group of non-pregnant woman. Average systolic and diastolic blood pressure was significantly raised in preeclamptic women compare with normal pregnant and non-pregnant women.

Table -2 shows the serum thyroid status (TT3, TT4, FT3, FT4 and TSH) of non-pregnant women, normotensive pregnant women and preeclamptic women. The mean serum TT3 and TT4 in normotensive pregnancy were significantly higher compared to that of non-pregnant subjects. In preeclamptic women, the mean serum TT3 and TT4 levels were significantly raised than in non-pregnant subjects. But compared to the level of women with normotensive pregnancy TT4 level was marginally raised when TT3 was significantly lower $(\mathrm{P}<0.05)$. Mean TSH levels were significantly raised in normotensive pregnancy than in non-pregnant woman $(p<0.001)$. Mean TSH level for preeclamptic women were significantly higher than that in normal pregnancy and in non-pregnant woman $(\mathrm{P}<0.001)$.

The mean serum FT4 level was significantly higher in preeclampsia compared to non-pregnant women $(\mathrm{P}<$ 0.001), but FT4 levels almost similar between women with normotensive pregnancy and those with preeclampsia. Serum FT3 was significantly higher in normotensive pregnancy than in non-pregnant women. The mean FT3 level in preeclampsia is significantly lower than that in normotensive pregnant women $(\mathrm{P}<0.01)$.

\section{Discussion}

In our study we evaluated thyroid hormone levels in normal pregnancy and in preeclamptic women. Evaluation in serum thyroid hormone levels in pregnancy indicates an important modification of thyroid activity in pregnancy [8]. In our study serum TT4 and TT3 were significantly higher in pregnant women compared to non-pregnant subjects, whereas FT4 and FT3 were almost same in both groups. The increase in serum binding forms of thyroid hormones may be due to increase in the circulatory levels of thyroid binding globulin (TBG). During pregnancy, increased estrogen levels cause increased production of TBG by the liver. High estrogen on the other hand, due to oligosaccharide modification, reduces peripheral degradation of thyroid binding globulin (TBG). As a result the content of TBG in the serum is increased. As the binding capacity of plasma is increased the total plasma concentration of thyroid hormone is increased. Despite this free thyroid hormone level remain unchanged and hyperthyroidism does not occur. Different studies are controversial regarding free thyroid hormone levels during pregnancy. In our study there is no significant change in free thyroid hormones between non-pregnant and pregnant women; The study then contributes to the ongoing controversy [10]. In our present study serum TT4 and FT4 is slightly higher in preeclamptic women then in women with normotensive pregnancy. But it is statistically not significant. However, compared to women with normotensive pregnancy, women with preeclampsia did have statistically significant lower TT3 and FT3 levels. In preeclampsia most affected organs are brain, liver and kidneys. Functional disorder in these organs are evident in preeclampsia [11]. The liver and kidney are the most important organs in peripheral deiodination of T4 to T3. So, the reduced extra thyroidal conversion of $\mathrm{T} 4$ to $\mathrm{T} 3$ was the cause of the non-significant higher T4 levels and significant lower T3 levels in preeclampsia.

\section{Conclusion}

The main findings of our present study are statistically significant higher number of preeclamptic women who had high TSH levels. Thyroid disorders are predisclosing factors for the development of preeclampsia. If the TSH level above $5 \mathrm{mIU}$ per $\mathrm{ml}$ then the risk of developing preeclampsia is 4.8 times higher. This high risk potential marker of preeclampsia needs further investigation.

\section{Reference :}

[1] Cunnigham FG, Leveno KL, Bloom SL Hauth JC, Gilstrap LC and Wenstrom KD.et al.Hypertensive disorders in pregnancy. In: Cunnigham FG, Leveno KL, Bloom SL, editors. Williams Obstetrics. 22nd ed. NewYork; McGraw-Hill; 2005: chap 34, 1237.

[2] Sibai 8, Dekker G, Kupferminc M. Pre-eclampsia. Lancet. 2005; 365:785-99.

[3] Bellany, L., Casas, J.P., Hingorani, A.D and Williams, D.J.: Preeclampsia and risk of cardiovascular diseased cancer in later life: systematic review and meta-analysis. Br. Med. J., 335, 974- 974, 2007.

[4] Solomon, C.G and Seely, E.W.: Brief review: Hypertension in pregnangcy : A manifestation of the insulin resistance syndrome ? Hypertension, $37 ; 232-239,2001$.

[5] Kumar, A., Ghosh, B.K and Murthy, N.S.: Maternal thyroid hormonal status in preeclampsia, Indian J.Med. Sci., 59, 57-63, 2005.

[6] Qublan, H.S., Al-Kaisi, I.J., Hindawi, I.M., Hiasat, M.S., Awamleh, I and Hamaideh, A.H., et al.: Severe preeclampsia and maternal thyroid function. J. Obstet. Gynaecol., 23, 244-246, 2003. 
[7] Kaya, E., Sahin, Y., Ozkececi, Z and Pasaoglu, H.:* Relation between birth weight and thyroid function in preelampsia-eclampsia. Gynaecol. Obstet. Invest. ,37, 30-33, 1994.

[8] Rahman, M.H., Chowdhury, M.A and Alam, M.T.: Serum thyroxine and triiodothyronine levels in normal pregnancy and preeclampsia. TAJ, 20(1), 06-10, 2007.

[9] Sapin R, Schlienger JL (2003). Thyroxine (T4) and triiodothyronine (T3) determinations: techniques and value in the assessment of thyroid function. Ann. Biol. Clin. (Paris). 61:411-420.

Table - 1: Demographic characteristics of study population in non-pregnant, norotensive pregnant and preeclamptic subjects

\begin{tabular}{|c|c|c|c|}
\hline Parameter & Non-pregnant women $(n=30)$ & $\begin{array}{l}\text { Normotensive pregnant women } \\
(\mathrm{n}=30)\end{array}$ & Preeclamptic women $(n=30)$ \\
\hline Mean age (years) & $25 \pm 4$ & $27 \pm 7$ & $26 \pm 5$ \\
\hline Weight $(\mathrm{kg})$ & $46 \pm 8$ & $55 \pm 5$ & $59 \pm 6$ \\
\hline Body mass Index $\left(\mathrm{kg} / \mathrm{m}^{2}\right)$ & $22 \pm 2$ & $25 \pm 4.1^{* *}$ & $27 \pm 5.1^{\square \square \square}$ \\
\hline $\begin{array}{l}\text { Average systolic blood pressure } \\
(\mathrm{mm} \mathrm{Hg})\end{array}$ & $116 \pm 2$ & $110 \pm 3^{\mathrm{NS}}$ & 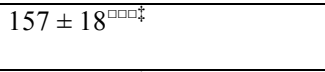 \\
\hline $\begin{array}{l}\text { Average diastolic blood pressure } \\
(\mathrm{mm} \mathrm{Hg})\end{array}$ & $76 \pm 1$ & $78 \pm 3^{\mathrm{NS}}$ & $116 \pm 11^{\text {口पवस }}$ \\
\hline $\begin{array}{l}\begin{array}{l}\text { Average period of } \\
\text { (weeks) }\end{array} \\
\end{array}$ & - & 37 weeks & 36 weeks. \\
\hline
\end{tabular}

Values are given as mean \pm SD.

Preeclamptic women compared with non-pregnant women $\left({ }^{\square} \mathrm{p}<0.001\right)$

* Normotensive pregnant women compared with non-pregnant women. (**p<0.01, ${ }^{\text {NS }}$ - Not significant)

$*$ Preeclampsia women compared with normotensive pregnant women. $(* p<0.001)$.

Table - 2: Mean values of TT3, TT4, FT3, FT4 and TSH in non-pregnant, normotensive pregnant and preeclamptic women

\begin{tabular}{|l|l|l|l|}
\hline Parameter & Non-pregnant women $(\mathrm{n}=30)$ & $\begin{array}{l}\text { Normotensive pregnant women } \\
(\mathrm{n}=30)\end{array}$ & Preeclamptic women $(\mathrm{n}=30)$ \\
\hline TT3 $(\mathrm{ng} / \mathrm{ml})$ & $0.85 \pm 0.14$ & $2.13 \pm 0.44^{*}$ & $1.83 \pm 0.39^{\ddagger \square}$ \\
\hline TT4 $(\mathrm{microgm} / \mathrm{dl})$ & $7.02 \pm 2.21$ & $12.61 \pm 5.12^{*}$ & $12.71 \pm 5.02^{\ddagger \mathrm{NS}}$ \\
\hline FT3 $(\mathrm{Pg} / \mathrm{ml})$ & $2.62 \pm 0.69$ & $3.51 \pm 1.18^{*}$ & $2.69 \pm 1.11^{\ddagger \mathrm{a}}$ \\
\hline FT4 $(\mathrm{ng} / \mathrm{ml})$ & $1.14 \pm 0.51$ & $2.36 \pm 0.89^{*}$ & $2.39 \pm 0.71^{\ddagger \mathrm{NS}}$ \\
\hline TSH $(\mathrm{mIU} / \mathrm{ml})$ & $2.12 \pm 1.21$ & $3.82 \pm 2.28^{*}$ & $5.22 \pm 2.48^{\ddagger \square \square}$ \\
\hline
\end{tabular}

Values are given as mean \pm SD from 30 subjects in each group.

* Normal pregnant women compared with non-pregnant women $(* \mathrm{p}<0.001)$

$\$$ Pre-eclamptic subjects compared with non-pregnant subjects. $\left({ }^{\ddagger} \mathrm{p}<0.001\right)$

$\square$ Pre-eclamptic subject compared with normotensive pregnant women.

$\left(\mathrm{p}<0.05,{ }^{\square} \mathrm{p}<0.01{ }^{\square} \mathrm{p}<0.001, \mathrm{NS}-\right.$ Not significant $)$ 